\title{
Preclinical Gene Therapy Studies for Hemophilia Using Adenoviral Vectors
}

\author{
Lieven Thorrez, ${ }^{1}$ Thierry VandenDriessche, Ph.D., ${ }^{1}$ Désiré Collen, M.D., Ph.D., ${ }^{1}$ \\ and Marinee K.L. Chuah, Ph.D.,
}

Hemophilia A and B are hereditary coagulation defects resulting from a deficiency of factor VIII (FVIII) and factor IX (FIX), respectively. Introducing a functional FVIII or FIX gene could potentially provide a cure for these bleeding disorders. Adenoviral vectors have been used as tools to introduce potentially therapeutic genes into mammalian cells and are by far the most efficient vectors for hepatic gene delivery. Long-term expression of both FVIII and FIX has been achieved in preclinical (hemophilic) mouse models using adenoviral vectors. Therapeutic levels of FVIII and FIX also have been achieved in hemophilic dogs using adenoviral vectors and in some cases expression was long-term. The performance of earlier generation adenoviral vectors, which retained residual viral genes, was compromised by potent acute and chronic inflammatory responses that contributed to significant toxicity and morbidity and short-term expression of FVIII and FIX. The development of improved adenoviral vectors devoid of viral genes (gutless or high-capacity adenoviral vectors) was therefore warranted, which led to a significant reduction in acute and chronic toxicity and more prolonged expression of FVIII and FIX. Strategies aimed at making these vectors safer and less immunogenic and their implications for hemophilia gene therapy are discussed in this review.

KEYWORDS: Hemophilia A, hemophilia B, gene therapy, adenoviral vector

Objectives: On completion of the article the reader should be able to (1) list some of the problems encountered with early generations of adenoviral vectors, and (2) conceptualize results obtained with high-performance adenoviral vectors in several animal models of hemophilia.

Accreditation: Tufts University School of Medicine (TUSM) is accredited by the Accreditation Council for Continuing Medical Education to provide continuing medical education for physicians. TUSM takes responsibility for the content, quality, and scientific integrity of this CME activity.

Credit: TUSM designates this educational activity for a maximum of 1 Category 1 credit toward the AMA Physicians Recognition Award. Each physician should claim only those credits that he/she actually spent in the educational activity.

Gene Therapy in Hemophilia A and B in Animals and Humans: Current Status and Perspective; Editor in Chief, Eberhard F. Mammen, M.D.; Guest Editors, Thierry VandenDriessche, Ph.D., and Marinee K.L. Chuah, Ph.D. Seminars in Thrombosis and Hemostasis, volume 30, number 2, 2004. Address for correspondence and reprint requests: Marinee K.L. Chuah, Ph.D., Center for Transgene Technology and Gene Therapy, University of Leuven, Flanders Interuniversity Institute for Biotechnology (VIB), University Hospital Gasthuisberg, Herestraat 49, B-3000 Leuven, Belgium. E-mail: marinee.chuah@med.kuleuven.ac.be. ${ }^{1}$ Center for Transgene Technology and Gene Therapy, University of Leuven, Flanders Interuniversity Institute for Biotechnology (VIB), University Hospital Gasthuisberg, Leuven, Belgium; ${ }^{2}$ Professor. Copyright $(C) 2004$ by Thieme Medical Publishers, Inc., 333 Seventh Avenue, New York, NY 10001, USA. Tel: +1(212) 584-4662. 0094-6176,p;2004,30,02,173,183, ftx,en;sth00957x. 
Hemophilia A and B are hereditary X-chromosome-linked bleeding disorders, due to a deficiency in coagulation factor VIII (FVIII) or factor IX (FIX), respectively. Recurrent bleedings in the joints, muscles, and internal organs are the hallmark of severe hemophilia. ${ }^{1}$ The liver is the natural site of production of FVIII and FIX, although a significant amount of FVIII also is synthesized in the kidney. ${ }^{2}$ Currently, patients with hemophilia are treated in response to bleeding episodes with infusion of plasma-derived or, more recently, recombinant FVIII or FIX concentrates. Both the life expectancy and the quality of life of patients have been markedly improved by protein-replacement therapy. Nevertheless, treated patients are still at risk of lifethreatening bleeding episodes and chronic joint damage, given that treatment is restricted by the limited availability and high cost of purified clotting factors. The burden of regular venous injections is high and an important side effect of clotting factor substitution therapy is that some patients develop neutralizing antibodies against FVIII or FIX. Despite great improvement in screening and production methods of plasma-derived clotting factors, reports of transmission of viruses ${ }^{3,4}$ and the potential risk of infectious prion transmission ${ }^{5}$ still raise safety concerns. The limitations of current treatments justify the development of gene therapy for hemophilia, which may ultimately provide a cure.

Since the first developments of gene therapy, hemophilia has been an attractive disease model for several reasons. First, it is caused by a single gene defect. Second, the therapeutic window is relatively broad. Experience with prophylactic regimens of protein concentrates during the last 30 years has established that continuous maintenance of circulating levels of clotting factor $>1 \%$ is adequate to prevent most of the mortality and much of the morbidity associated with the disease. ${ }^{6}$ Third, the availability of animal models, including FVIII and FIX-knock-out mice ${ }^{7-10}$ and hemophilia $\mathrm{A}$ and $\mathrm{B}$ dogs ${ }^{11,12}$ which mimic the clinical symptoms of hemophilia, facilitates preclinical gene therapy efficacy and safety studies. Finally, determination of therapeutic efficacy is straightforward in the case of hemophilia, given that circulating levels of clotting factors are easy to measure and correlate well with clinical manifestations of the disease.

Gene therapy for hemophilia requires the use of a gene delivery system that is efficient, safe, nonimmunogenic, and allows for long-term protein expression. This must compare favorably with existing protein replacement therapies. Adenoviral vectors are by far the most efficient gene delivery vehicle to introduce genes into hepatocytes. However, adenoviral vectors can trigger inflammatory responses, which compromise their safety and efficacy. The properties of adenoviral vectors and modifications to the vector system with specific emphasis on hemophilia gene therapy will be discussed.

\section{ADENOVIRAL VECTOR DEVELOPIMENT}

\section{Properties of Adenoviruses}

Human adenoviruses are nonenveloped, doublestranded DNA viruses belonging to the Adenoviridae family. The virion is 80 to $90 \mathrm{~nm}$ in diameter with a spiked icosahedral morphology. Adenovirus infects target cells by attachment to the coxsackie and adenovirus receptor on the cell surface, ${ }^{13}$ internalization via clathrin-coated pits into endosomes, escape of the virion into the cytoplasm by endosomolysis, translocation to the nuclear membrane via nuclear targeting signals within the capsid polypeptides, and transport of the viral genome into the cell nucleus, where the viral genome remains episomal. Adenoviruses have several attractive features that make them particularly well suited for vector development and gene therapy. The genome has a size of $36 \mathrm{~kb}$, which after (partial) deletion leaves a relatively large packaging capacity. Adenoviruses can infect and express genes at high levels in many different cell types and host cell replication is not required for expression, so nondividing cells such as hepatocytes are readily infected. There are at least 50 different human serotypes, subgrouped A to $G$, which are commonly associated with mild diseases. Most adenoviral vectors currently used are derived from serotypes 2 and 5, which are endemic and cause upper respiratory tract infection. No known malignant tumors have resulted from adenovirus infection. Given that they have been used in live virus vaccine studies for many years without problems, they have a long-standing safety record.

The difference between an adenovirus and its cognate vector is that the parental virus can replicate and infect other cells after infection, whereas adenoviral vectors can enter a cell, but cannot use the cell to replicate. This impaired replication is due to the lack of at least one of the essential viral regulatory genes, which is replaced by the gene of interest, in casu FVIII or FIX. Although adenoviral vectors cannot replicate, they do retain all of the other essential properties, including the tropism of the parental viruses from which they are derived. Adenoviral vectors are relatively easy to manufacture at high concentrations $\left(>10^{10}\right.$ infectious units $[\mathrm{iu}] / \mathrm{mL}$ ). They are well suited for hepatic gene delivery but their main disadvantage is that the host immune response limits the duration of transgene expression and the ability to readminister the vector. A second inherent limitation to the duration of transgene expression is because the adenoviral DNA is not integrated into the host genome but is maintained episomally. Hence, dividing cells will gradually lose the adenoviral vector along with its potentially therapeutic gene. However, this also implies that there is virtually no risk of neoplastic transformation caused by insertional mutagenesis. 


\section{Early-Generation Adenoviral Vectors}

The first-generation adenoviral vectors that were developed contained a deletion of the entire $E 1 A$ and part of the $E 1 B$ regions of the adenoviral genome ${ }^{14,15}$ (Fig. 1). This deletion allowed for insertion of an expression cassette up to $8 \mathrm{~kb}$. The $\mathrm{E} 1 \mathrm{~A}$ proteins are the first to be expressed de novo upon infection with wild-type adenovirus and constitute an essential master switch to turn on adenoviral gene expression. Expression of E1A initiates adenoviral replication and activates adenoviral transcription. The E1 and other missing genes necessary for vector assembly are complemented in trans using appropriate packaging cells that express these genes. ${ }^{16}$ First-generation adenoviral vectors retain the immediate $5^{\prime}$ end of the viral genome, including the left inverted terminal repeat and encapsidation signal, required for packaging and the overlapping $E 1$ enhancer, in addition to all other viral genes. These genes are still expressed at low levels even in the absence of E1, presumably as a result of activation by cellular E1-like proteins. Furthermore, acute and chronic toxic and lethal effects are observed frequently in nonhuman primates and other animals (including mice, rabbits and dogs) that receive high doses of replication-deficient adenoviral vectors. ${ }^{17,18}$ Finally, several clinical trials based on adenoviral vectors had to be discontinued because of acute inflammatory responses and severe morbidity and mortality $^{19}$ in some patients.

Given that the cells transduced with E1-deleted recombinant adenoviral vectors appeared to be eliminated by cytotoxic T-lymphocytes (CTL) directed toward late viral gene products, it was thought that this cellular immune response could be attenuated if not completely abolished by further reducing viral gene expression. This was initially accomplished by alteration or deletion of additional early viral genes such as $E 2$ or $E 4^{20-23}$ (Fig. 1). Incorporation of an E2A deletion or $E 2 A$ temperature-sensitive mutation into an $E 1$-deleted adenoviral vector did not improve persistence of transgene expression. ${ }^{24,25}$ Despite the fact that these secondgeneration vectors did not reveal any detectable de novo vector DNA synthesis or de novo viral gene expression in transduced cells, there was no significant difference in gene transfer and expression compared with first-generation adenoviral vectors. ${ }^{26} \mathrm{~A}$ concern related to intravenous administration is the potential of germline modification. However, no evidence could be found for transduction of spermatogonia after intravenous administration of E1/E4 deleted adenoviral vectors. ${ }^{27}$ Progressive deletion of the adenoviral genome $(E 1 / E 2 A / E 3$ deletion or $E 1 / E 4 / E 3$ deletion) did not extend the in vivo persistence of the transduced cells and did not reduce the specific antiviral cellular and humoral immune response compared with first-generation vectors. ${ }^{28}$ Further attenuation of the adenoviral vector backbone by removal of $E 1 / E 2 / E 3 / E 4$ diminished vector toxicity; however, the duration of transgene expression was reduced. $^{29}$

\section{EARLY-GENERATION ADENOVIRAL VECTORS EXPRESSING FVIII}

FVIII is a large, complex protein, which is relatively difficult to express. The FVIII cDNA contains sequences that repress its expression. ${ }^{30,31}$ FVIII protein is transported inefficiently from the endoplasmic reticulum to the Golgi apparatus, ${ }^{32}$ and the protein is extremely

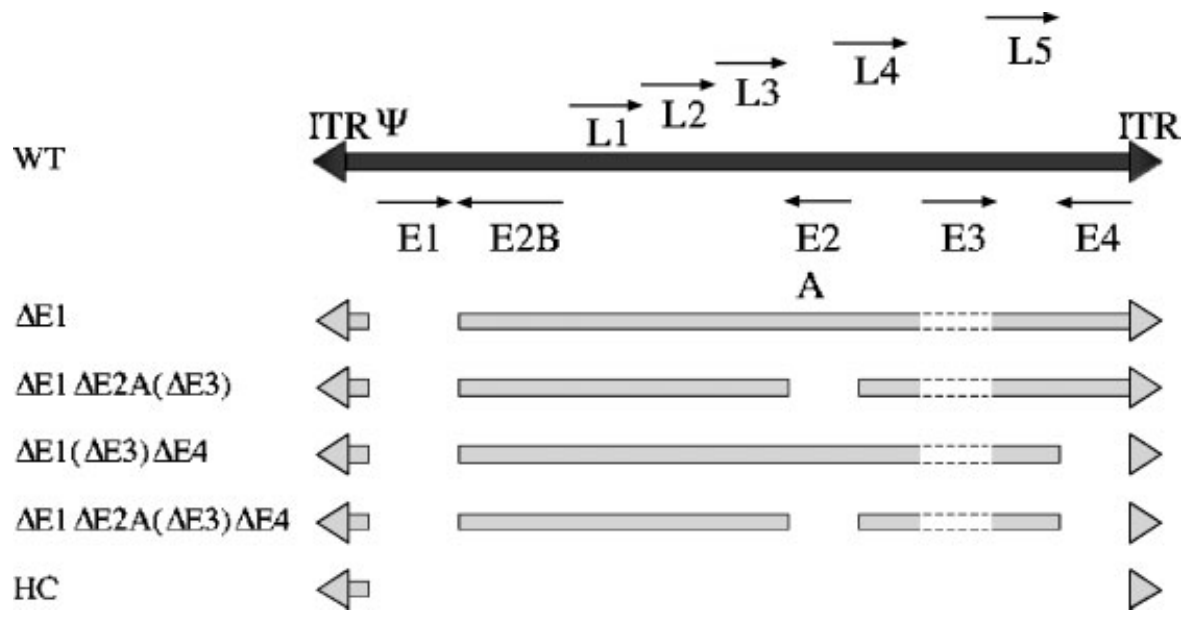

Figure 1 Comparison of deletions in the adenoviral genome for the different generations of adenoviral vectors. To make the wild-type (WT) adenovirus replication deficient, first a deletion in the E1 region was introduced and optionally also in the E3 region. Given that lowlevel adenoviral gene expression was apparent in these first-generation vectors, deletions in E2A (or temperature sensitive E2A mutations) or $E 4$ were introduced. In an attempt to trim the adenoviral genome further, vectors containing both E2 and E4 deletions in addition to the $E 1$ (and E3) deletion were generated. In contrast to these earlier generation adenoviral vectors, high-capacity (HC) vectors do not contain any adenoviral genes, but only retain the inverted terminal repeats (ITR) and the packaging signal. 
sensitive to proteolytic degradation if not stabilized by von Willebrand factor. The $\mathrm{B}$ domain is not required to produce functional FVIII, so in most studies the $4.3-\mathrm{kb}$ $\mathrm{B}$-domain-deleted $F V I I I \mathrm{cDNA}$ is used, which results in increased FVIII expression levels.

Intravenous administration of an early-generation $E 1 / E 3$-deleted or $E 1 / E 2 a / E 3$-deleted adenoviral vector in which the human or canine B-domain-deleted FVIII cDNA was driven by an albumin promoter to normal or hemophilic mice resulted in expression of therapeutic and even physiologic levels of biologically active FVIII, which corrected the bleeding deficiency in the hemophilic mice. ${ }^{33-38}$ Although no antibodies to human FVIII were detected, FVIII levels gradually declined to basal levels, which was at least partly due to dosedependent vector toxicity. Intravenous injection of human or canine FVIII early-generation E1/E3-deleted adenoviral vectors into hemophilia $\mathrm{A}$ dogs resulted in short-term phenotypic correction and expression of therapeutic levels of human or canine FVIII, ${ }^{17,39}$ peaking at $60 \mathrm{U} / \mathrm{mL}$. However, FVIII expression was transient because of the development of antihuman or canine FVIII-neutralizing antibodies, possibly in combination with acute and chronic liver toxicity. Even when an autologous murine FVIII gene was administered using E1/E3-deleted adenoviral vectors to FVIII-deficient mice that expressed nonfunctional FVIII heavy chains, expression was short term because a humoral and cellular immune response. ${ }^{40,41}$ Hence, despite the presence of endogenous FVIII protein, the immune system still recognized a species-specific transgene protein as a neo-antigen, eliciting an immune response. Short-term correction of FVIII deficiency in a murine hemophilia A was also observed after delivery of adenovirus murine FVIII in utero, but in this case the gradual loss in expression mainly was due to the postnatal hepatocyte proliferation, given that adenoviral vectors do not integrate. $^{41}$

Experiments in adult primates have shown that therapeutic levels of FVIII could be obtained with an $E 1 / E 2 a / E 3$-deleted vector. ${ }^{42}$ Because the experiment only lasted 1 week it was not clear how long FVIII expression lasted. FVIII was only expressed following injection of a relatively high vector dose $\left(3 \times 10^{12}\right.$ viral particles [vp] $/ \mathrm{kg}$ ). Transient elevations of liver enzymes, and histological evidence of liver inflammation, anemia, thrombocytopenia, and lymphoid and marrow hyperplasia were noted. In a study with four cynomolgus monkeys, peak FVIII levels of $100 \mathrm{ng} / \mathrm{mL}$ were observed following an injection with $3 \times 10^{12} \mathrm{vp} / \mathrm{kg}$ of an E1/E2/ E3-deleted vector. ${ }^{43}$ Expression persisted for 14 to 28 days and the vector copy number declined 10-fold between day 7 and 56. Two of the animals did not develop antibodies to FVIII, but an increase in liver enzymes and interleukin 6 (IL-6) levels and a platelet decrease occurred in all animals.

\section{EARLY-GENERATION ADENOVIRAL VECTORS EXPRESSING FIX}

The 3-kb FIX cDNA is much easier to express than FVIII, but the normal plasma level is considerably higher $(5 \mu \mathrm{g} / \mathrm{mL})$. Early-generation adenoviral vectors expressing the canine or human $F I X$ cDNAs were injected intravenously in hemophilic $\operatorname{dogs}^{44}$ and nor$\mathrm{mal}^{45,46}$ and hemophilic mice. ${ }^{47}$ This resulted in efficient liver transduction and supraphysiologic levels of FIX, which transiently corrected the bleeding diathesis in the hemophilia B mice and dog models. However, levels slowly declined to baseline because of cellmediated and humoral immune responses, as confirmed in independent studies. ${ }^{48}$ Levels were not re-established by a second vector injection because of high amounts of circulating antibodies that neutralized the vector upon rechallenge. Intramuscular administration of an adenoviral vector efficiently activated FIX-specific CTLs and $\mathrm{T}$ helper cells of both Th1 and Th2 subsets, leading to inflammation and destruction of transduced muscle tissue and activation of $\mathrm{B}$ cells. ${ }^{49}$

Adenoviral vector-mediated factor IX gene transfer in rhesus macaques gave rise to transient nearphysiologic levels of human FIX after 4 days $(4 \mu \mathrm{g} / \mathrm{mL})$ but levels decreased within 3 weeks. The expression response was linear with infusion of $8 \times 10^{10}$ to $8 \times$ $10^{11}$ IU. Despite the fact that human FIX protein injections did not induce antibodies given the high degree of homology between human and macaque FIX, ${ }^{50}$ antibodies to FIX were induced, suggesting an immune adjuvant effect of the first-generation E1/E3-deleted adenoviral vector. ${ }^{18}$ At a dose of $1.2 \times 10^{13} \mathrm{vp} / \mathrm{kg}$, first-generation vectors were shown to cause acute symptoms, extreme thrombocytopenia, increased liver enzymes, and prominent elevation of interleukin 6 (IL-6) and tumor necrosis factor alpha (TNF- $\alpha)$, causing a baboon to become moribund 48 hours postinjection. ${ }^{51}$ Injury to the vascular endothelium was the most prominent histological abnormality. In addition, coagulopathy caused by persistent hypofibrinogenemia ${ }^{18}$ also was apparent.

To prolong FIX transgene expression, administration of the adenoviral vector was combined with immunosuppressive drugs such as cyclosporin A and cyclophosphamide, which allowed therapeutic levels to persist for longer periods, but levels progressively declined to pretreatment levels. ${ }^{48,52}$ Immunosuppressive strategies designed to block the formation of antibodies to the viral capsid did permit a successful readministration of vector in mice. ${ }^{53,54}$ However, nonspecific immunosuppressive treatments are not desirable for application in humans; the immunosuppressive treatment might also diminish the immune response against naturally occurring wild-type adenoviral infections.

It would be preferred to modify the vector components instead. A recombinant adenovirus-expressing canine FIX was therefore modified to contain a 
temperature-sensitive mutation (ts125) in the DNA binding protein encoded within the viral $E 2 A$ region, leading to reduced late adenoviral gene expression. ${ }^{25}$ The effects of the inclusion of the ts 125 mutation on transgene expression in vivo were evaluated in $\mathrm{BALB} / \mathrm{c}$ mice and hemophilia $\mathrm{B}$ dogs by comparison with adenoviral vectors containing the same transgene but lacking the $t s 125$ mutation. No significant differences in the duration of transgene expression were observed in either animal model. The inability of the $t s 125$ mutation to prolong transgene expression in these two animal models suggests that further modification of the vector backbone is required to achieve more prolonged gene expression.

In conclusion, these data indicated that first- and second-generation adenoviral vectors were associated with acute and chronic toxicity and did not support long-term expression of FVIII or FIX in preclinical animal models. The hepatotoxic effects of adenoviral vectors could be circumvented, but not eliminated, by using stronger FVIII- or FIX-expression cassettes, allowing the use of lower vector doses.

\section{Development of High-Capacity Adenoviral Vectors}

The ultimate adenoviral vector modification comprises a vector containing only the cis-acting elements necessary for replication and packaging, but lacking all adenoviral genes. ${ }^{55} \mathrm{~A}$ comparison with earlier generation adenoviral vectors showing the deletions in the viral genome is depicted in Figure 1. High-capacity (HC) adenoviral vectors, also called gutted or gutless vectors can theoretically accommodate up to $\sim 37 \mathrm{~kb}$ of insert. ${ }^{56-61}$ Production of high-capacity adenoviral vectors depends on the use of helper viruses that provide all missing functions in trans but cannot be packaged efficiently because of mutations in the packaging signal ${ }^{56,62-65}$ (Fig. 2). High-capacity vectors could give rise to prolonged transgene expression. ${ }^{58,59,66-72}$ These latest generation high-capacity vectors were associated with significantly reduced acute and chronic hepatotoxicity and reduced inflammatory responses compared with first-generation adenoviral vectors, ${ }^{59}$ even in large animal models such as primates or dogs,${ }^{55,71}$ which are more susceptible to the toxic side effects of adenoviral vectors than mice. ${ }^{38,39,73}$
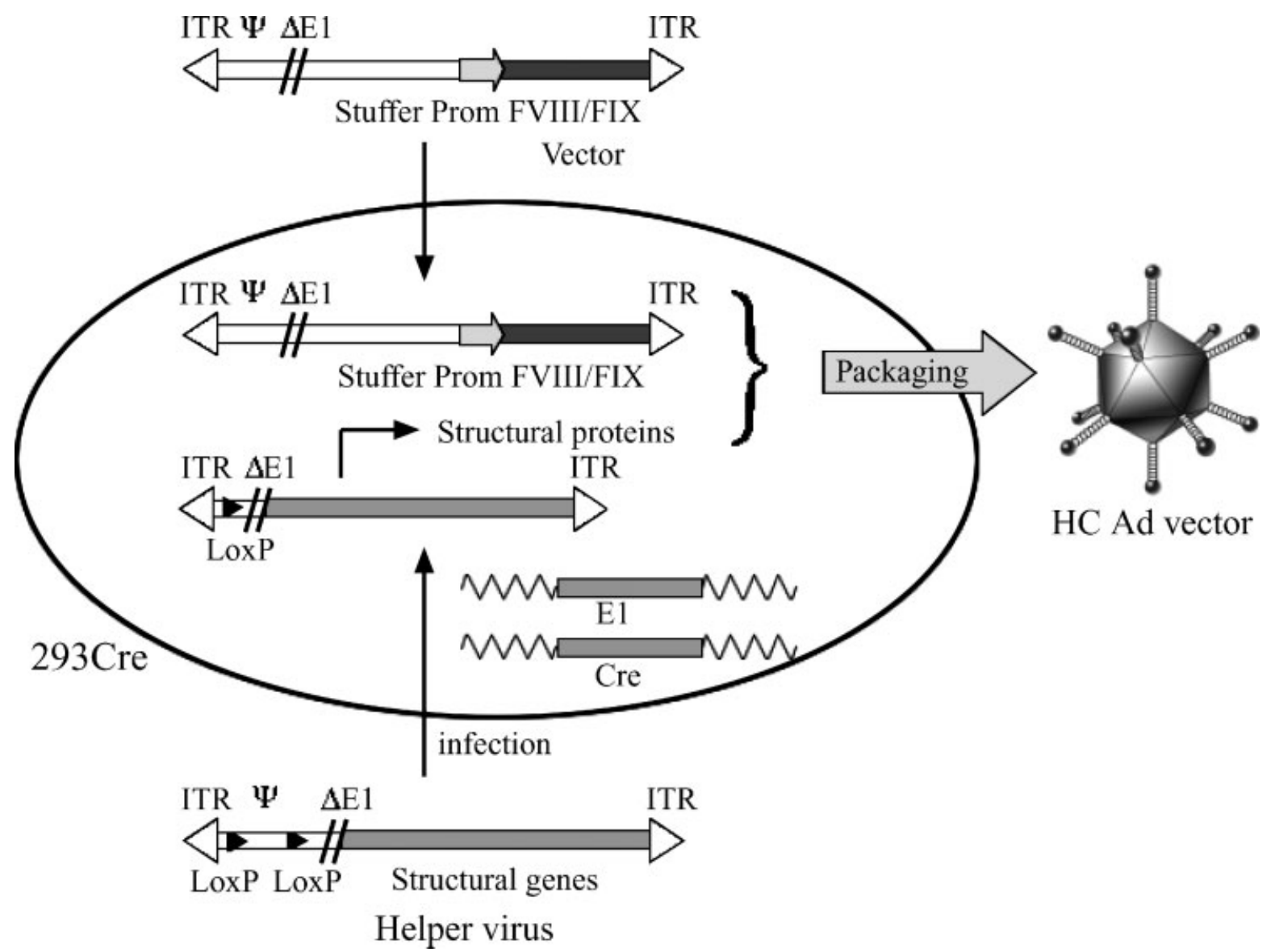

Figure 2 Production of high-capacity $(\mathrm{HC})$ vectors. 293Cre cells are infected with a helper virus containing a packaging signal flanked by loxP sites. Cre activity in the 293Cre cells results in excision of the packaging signal, rendering the helper packaging deficient. The helper virus, aided by the E1 sequence in the $293 \mathrm{Cre}$ cells, provides the structural genes necessary for adenoviral particle assembly. The cotransfection with the vectorconstruct results in preferential packaging of the vector genome. The titer of the resulting $\mathrm{HC}$ adenoviral vectors can be increased by serial passage in helper virus infected 293Cre cells. ITR, inverted terminal repeat; Prom, promoter; FVIII, factor VIII; FIX, factor IX. 
In particular, the induction of proinflammatory cytokines IL-6 and TNF- $\alpha$ was significantly less following high-capacity adenoviral vector administration than when early-generation vectors were used. ${ }^{72}$ Transgene expression was also more prolonged with high-capacity adenoviral vectors when compared side by side with early-generation adenoviral vectors. ${ }^{58,59,70} \mathrm{It}$ is not certain whether these vectors could give rise to life-long transgene expression because several studies demonstrated a slow but significant decline in transgene expression. ${ }^{68,70,72}$ This may be due to the low turnover rate of hepatocytes leading to the gradual loss of the highcapacity adenoviral vector. The absence of de novo expression of adenoviral gene expression in the cells that are transduced with the $\mathrm{HC}$ adenoviral vectors is expected to prevent the induction of CTL, provided the transgene in itself is nonimmunogenic. Paradoxically, when de novo adenoviral gene expression by first-generation adenoviral vectors is blocked by psoralen treatment and ultraviolet cross-linking, CTL responses specific for the transduced target cells can still be induced. ${ }^{74}$ It has therefore been proposed that the vector particles themselves could be processed and presented in a major histocompatibility complex class I-restricted fashion to CTL effectors.

\section{HC VECTORS EXPRESSING FVIII}

When compared with first-generation adenoviral vectors, $\mathrm{HC}$ vector-treated mice displayed 10 -fold higher FVIII expression levels that were sustained for at least 9 months. ${ }^{70}$ The expression cassette was composed of an albumin promoter, an intron, the $\mathrm{B}$ domain-deleted FVIII cDNA, and the SV40 poly(A) signal. At a dose of $6 \times 10^{10} \mathrm{vp}$, the HC vector-induced FVIII expression $>1 \mathrm{U} / \mathrm{mL}$, which declined 10-fold over a period of 40 weeks. Antibodies against FVIII were not detected. Both the first-generation and the $\mathrm{HC}$ vector were also administered at doses of $1.2 \times 10^{11}$ and $3 \times 10^{11}$ vp to evaluate toxicity. At the highest dose, both vectors displayed a mild increase in liver enzymes, which returned to normal after 3 days. However, the first-generation adenoviral vector triggered a second increase in liver enzymes about a week after vector injection, which returned to baseline after 1 month. This second peak in transaminases was absent when the $\mathrm{HC}$ adenoviral vector was used. Hence, it is likely that the initial burst in transaminases reflects acute toxicity that is attributable to the capsid input, whereas the secondary prolonged liver enzyme elevation possibly is due to de novo adenoviral gene expression from the first-generation vector.

The first described FVIII containing high-capacity adenoviral vector carried the full-length human FVIII cDNA under the control of the human $12.5-\mathrm{kb}$ albumin promoter. This $\mathrm{HC}$ adenoviral vector was injected at $10^{11}$ vp into FVIII-deficient mice and resulted in efficient hepatic gene transfer and long-term therapeutic FVIII expression (100-800 ng/mL) leading to phenotypic correction. ${ }^{66,68}$ However, expression dropped to undetectable levels in 5 out of 8 mice within 2 months after treatment due to induction of inhibitory antibodies to human FVIII. No significant vector-associated toxicities were detected in mice and dogs at doses as high as $3 \times 10^{11} \mathrm{vp} /$ mouse and $2.6 \times 10^{12} \mathrm{vp} / \mathrm{dog}$, but in the latter model, no detectable FVIII expression was obtained. At a dose of $3 \times 10^{12} \mathrm{vp} / \mathrm{kg}$, correction of the whole-blood clotting time in a hemophilic dog was seen. Low FVIII levels (up to $0.08 \mathrm{U} / \mathrm{mL}$ ) were obtained in non-human primates. ${ }^{75}$ However, transient hematological and hepatic toxicities were also observed at a dose of $4.3 \times 10^{12} \mathrm{vp} / \mathrm{kg}$ but not at $1.4 \times 10^{12} \mathrm{vp} / \mathrm{kg}$. One $\mathrm{pa}-$ tient suffering from severe hemophilia $\mathrm{A}$ has been treated with this $\mathrm{HC}$ adenoviral vector, which is discussed elsewhere in this issue (see the article by VandenDriessche et al). The patient appeared to express $\sim 1 \%$ of normal FVIII levels for several months. However, a transient inflammatory response with hematologic and liver abnormalities was observed that returned to normal values within 19 days. Due to these transient toxic effects, the trial was put on hold. ${ }^{76}$ These preclinical and clinical results indicate that further improvements of $\mathrm{HC}$ adenoviral vector technology is warranted.

We have recently generated an improved $\mathrm{HC}$ adenoviral vector that expressed unprecedented FVIII levels in mice, higher than any other gene therapy approach published to date. Injection of human and canine FVIII HC vectors driven by the $\alpha 1$-antitrypsin promoter in immunodeficient mice at doses ranging from $1.65 \times 10^{9}$ to $1.65 \times 10^{11}$ vp led to long term expression of $0.1 \mathrm{U} / \mathrm{mL}$ (lowest dose) to $>15 \mathrm{U} / \mathrm{mL}^{71}$ with peak levels up to $75 \mathrm{U} / \mathrm{mL}$. These levels are at least $20-40-$ fold higher than what has been achieved with a previous $\mathrm{HC}$ adenoviral vector that expressed full length FVIII from the albumin promoter (vide supra).

In immunocompetent hemophilic mice, initial FVIII expression levels using the highest vector dose were comparable to the levels obtained in immunodeficient hemophilic mice but then decreased to undetectable levels within 2 to 4 weeks, coinciding with induction of neutralizing antibodies and possibly also cellular immune responses (CTLs). IL-6 levels and platelet counts were not affected at a dose of $1.65 \times 10^{11} \mathrm{vp}$, however serum transaminase levels showed a significant peak at day 14 , possibly reflecting a CTL response.

The anti-FVIII immune response could be overcome and stable FVIII levels could be obtained in immunocompetent hemophilic mice by pretreatment with clodronate liposomes, which induces transient depletion of antigen-presenting cells (APCs), particularly Kupffer cells and splenic macrophages. In addition, transient APC depletion resulted in a 10 -fold increase in FVIII expression levels, and therapeutic $(0.1 \mathrm{U} / \mathrm{mL})$ FVIII levels could still be obtained at a vector dose as low 
as $1.65 \times 10^{8}$ vp. These results indicate that the innate immune compartment limits the therapeutic efficacy of $\mathrm{HC}$ adenoviral vectors. This reduced therapeutic efficacy is likely the combined result of a direct uptake of $\mathrm{HC}$ adenoviral vector particles by APCs in conjunction with the induction of a specific humoral immune response. Hence, the therapeutic window of $\mathrm{HC}$ vectors could be improved further by minimizing the interaction between $\mathrm{HC}$ vectors and APCs.

Upon injection of $3.6 \times 10^{11} \mathrm{vp} / \mathrm{kg}$ of this $\mathrm{HC}$ vector containing the canine FVIII gene into a hemophilia A dog, transient therapeutic FVIII levels (3 to 4\% of normal human levels) could be achieved. Inhibitory antibodies to FVIII could not be detected and there were no signs of hepatotoxicity or hematologic abnormalities. ${ }^{71}$ Long-term correction of hemophilia A was recently achieved in dogs that received a high dose of vectors wherein the FVIII gene was driven by the proximal human FVIII promoter with an upstream hepatocyte nuclear factor 1 (HNF1) concatemer. ${ }^{77}$ When this vector was administered at a dose of $1.25 \times 10^{12} \mathrm{vp} / \mathrm{kg}$, peak FVIII levels of $100 \mathrm{mU}(10 \%$ of normal) were observed, but in one dog, this level declined to baseline over a period of 2 months, and in another dog, levels of $10 \mathrm{mU} / \mathrm{mL}$ were observed stably over a period of 5.5 months. FVIII inhibitors were not detected in these dogs. However, this vector dose triggered transient thrombocytopenia and hepatotoxicity, measured by increased amino alanine transferase levels. A third dog that received only $5 \times 10^{11} \mathrm{vp} / \mathrm{kg}$ did not show any of these abnormalities. When a CMV promoter was used and $2 \times 10^{12} \mathrm{vp} / \mathrm{kg}$ was administered to a fourth dog, FVIII concentrations reached $19 \mathrm{U} / \mathrm{mL}$, but quickly declined below the detection limit, coinciding with generation of FVIII inhibitors. It is not certain whether this induction of antibodies is attributable to the higher toxicity associated with the vector dose, to the expression of FVIII in cells other than hepatocytes, or a combination of both. It has been proposed that for the CMV vector, a potent innate immune response elicited a danger signal, ${ }^{78}$ leading to activation of the adaptive immune system, whereas this was not the case with the liver-specific vector at lower dose.

\section{HC VECTORS EXPRESSING FIX}

An expression cassette consisting of a matrix attachment region, a liver-specific promoter, and a human FIX minigene was tested in both a $\mathrm{HC}$ and an early-generation vector. ${ }^{72}$ With the administration of $2 \times 10^{9}$ iu of either vector, FIX levels of up to $41 \mu \mathrm{g} / \mathrm{mL}$ were obtained; for the first-generation vector, this was 4 to 20 times higher than previous studies. During a period of 1 year, FIX concentrations slowly declined by 95\%, a level still of therapeutic significance. This decline was not attributable to the formation of antibodies, but to a 10 -fold drop of vector copy number, most probably caused by cell cycling and not by a CTL response. ${ }^{79}$ At this dose, IL- 6 and TNF- $\alpha$ concentrations were elevated in animals that received the early-generation but not the $\mathrm{HC}$ vector. At a dose of $1 \times 10^{8} \mathrm{iu}$, the $\mathrm{HC}$ vector still gave rise to therapeutic FIX levels (up to $1200 \mathrm{ng} / \mathrm{mL}$ ), whereas levels obtained with the first-generation vector were below $50 \mathrm{ng} / \mathrm{mL}$. This difference might be explained by de novo expression of adenoviral genes. The exact reason why this did not lead to antibody generation is uncertain, but is probably related to the low dose and the hepatocyte-specific expression cassette.

Subsequently, this expression cassette was modified with an additional matrix attachment region and with a canine instead of human FIX minigene. HC vectors were injected in two hemophilia $\mathrm{B}$ dogs at doses of 4.3 and $2.95 \times 10^{10} \mathrm{IU} / \mathrm{kg}$. Although a comparable dose gave rise to supraphysiological levels in mice, the peak FIX level was 2.2 and $0.53 \mu \mathrm{g} / \mathrm{mL}$ ( $44 \%$ and $11 \%$ of normal, respectively), which emphasizes a difference in therapeutic window among different animal models. Peak expression was followed in both dogs by a decline below therapeutic level after 2.5 months in the first dog and below the detection limit after 1 month in the second dog. There was no induction of a humoral immune response against FIX, consistent with the mouse results. In addition, no vector-related elevation of liver enzymes, no decrease in platelet counts, and no histologic abnormalities were seen.

\section{CONCLUSIONS AND PERSPECTIVES}

The safety profile and efficacy of adenoviral vectors for hemophilia gene therapy has improved significantly during the last few years. This has been accomplished largely by deleting all residual viral genes in the adenoviral backbone to generate $\mathrm{HC}$ adenoviral vectors. Although early-generation adenoviral vectors gave rise to therapeutic levels of FVIII and FIX in preclinical hemophilic mouse and dog models, they were associated with significant acute and chronic toxicity, inflammatory responses, and transient expression of FVIII and FIX, particularly in large animal models (hemophilic dogs and primates). In contrast, $\mathrm{HC}$ adenoviral vectors had a significantly improved safety profile and led to much more prolonged expression of FVIII or FIX compared with early-generation vectors. Although several studies in hemophilic dogs indicate that $\mathrm{HC}$ vectors yield therapeutic levels of FVIII or FIX with no or limited toxicity, ${ }^{71,75,77,80}$ it appears that the efficiency of $\mathrm{HC}$ adenoviral transduction is less efficient in dogs than in mice. The exact reason for this difference is not clear but may reflect differences in biodistribution, which may in turn be influenced by differences in anatomical barriers or differences in CAR receptor or $\alpha_{\mathrm{v}}$-integrin expression patterns among different species. ${ }^{81}$ Alternatively, the stability of adenoviral genomes, which is believed to be 
influenced by the adenoviral terminal protein, ${ }^{79}$ may be different in different species. In conclusion, although the use of animal models is extremely valuable in testing the consequences of gene therapy, the obtained results have to be interpreted with caution because the vectors may behave very differently in different species, making it particularly difficult to predict the outcome in clinical trials.

Although prolonged transgene expression has been achieved following $\mathrm{HC}$ adenoviral studies in mice, dogs, and baboons, ${ }^{5,66,68,70-72,77,80}$ transgene expression gradually declines. This may be due at least partly to hepatocyte turnover resulting in the gradual loss of adenoviral genomes. This warrants the development of integrating adenoviral vectors, for instance by using adeno-associated virus (AAV)-HC adenoviral hybrid systems or transposon technology. ${ }^{82-84}$ However, the use of an integrating vectors system raises other safety concerns related to the risk of insertional oncogenesis due to random integration, which is outlined elsewhere in this issue. ${ }^{85}$ Alternatively, Epstein-Barr virus-based episomal replication systems could be used in combination with HC adenoviral vector technology. ${ }^{86,87}$

One of the main obstacles of using adenoviral vectors, including $\mathrm{HC}$ vectors, is that they are readily taken up by APCs, particularly Kupffer cells and splenic macrophages, which consequently reduces the amount of adenoviral vector particles available for transducing hepatocytes. The uptake of adenoviral vectors by Kupffer cells likely accounts for the so-called threshold effect, implying that a critical threshold vector dose is required before the transgene product can be detected, which reflects a nonlinear relationship between vector dose and biological response. ${ }^{68,70,72,88,89}$ In addition, transduction of APCs possibly contributes to the induction of an immune response against the transgene product. ${ }^{6,70-}$ 72,78,88,90 Exposure of APCs to adenoviral vector particles may potentially lead to immune "danger" signals, ${ }^{78,90}$ whereby the capsid components may act as adjuvants ${ }^{91}$ that could contribute to an adaptive immune response directed against the vector and/or transgene product (in casu FVIII or FIX). Furthermore, inadvertent transgene expression in APCs could further enhance the immune response against the transgene product, suggesting that the use of a potent tissue-specific instead of a ubiquitously expressed promoter is warranted to circumvent this potential limitation. ${ }^{92,93}$

Systemic toxicity of adenoviral vectors may be linked directly to the activation and destruction of Kupffer cells, leading to a systemic activation of endothelial cells, responsible for the observed blood pressure decrease immediately following injection. ${ }^{94}$ Although toxicity and inflammatory responses were significantly reduced when $\mathrm{HC}$ adenoviral vectors were employed, compared with early-generation vectors, these side effects are not completely eliminated. Strategies aimed at reducing the uptake of vector particles into Kupffer cells and enhancing transduction in hepatocytes may therefore improve the therapeutic window of adenoviral vectors. One way to accomplish this is to modify the vector capsid, for instance with polyethylene glycol derivatives (i.e., PEGylation). ${ }^{95,96}$ An alternative approach to achieve retargeting is modification of the fiber protein ${ }^{97}$ or antibody-mediated retargeting to hepatocytes. ${ }^{98}$

Despite tremendous progress in developing improved adenoviral vectors for hemophilia $A$ and $B$ gene therapy, extensive preclinical studies are required to further improve their efficacy while improving their safety and reducing the risk of inhibitor formation.

\section{ACKNOWLEDGMENTS}

The research performed in our laboratory that was included in this review is made possible through a grant of the Flemish Interuniversity Institute of Biotechnology (VIB) and the Flemish Fund for Scientific Research (FWO). Lieven Thorrez is a recipient of a fellowship of the IWT (Instituut voor de aanmoediging van Innovatie door Wetenschap en Technologie in Vlaanderen).

\section{REFERENCES}

1. Kaufman RJ. Advances toward gene therapy for hemophilia at the millennium. Hum Gene Ther 1999;10:2091-2107

2. Hollestelle MJ, Thinnes T, Crain K, et al. Tissue distribution of factor VIII gene expression in vivo-a closer look. Thromb Haemost 2001;86:855-861

3. Yee TT, Cohen BJ, Pasi KJ, Lee CA. Transmission of symptomatic parvovirus B19 infection by clotting factor concentrate. Br J Haematol 1996;93:457-459

4. Teitel JM. Viral safety of haemophilia treatment products. Ann Med 2000;32:485-492

5. Evatt B. Creutzfeldt-Jakob disease and haemophilia: assessment of risk. Haemophilia 2000;6(suppl 1):94-99

6. Lofquist T, Nilsson IM, Berntorp E, Pettersson $H$. Haemophilia prophylaxis in young patients-a long-term follow-up. J Intern Med 1997;241:395-400

7. Bi L, Lawler AM, Antonarakis SE, et al. Targeted disruption of the mouse factor VIII gene produces a model of haemophilia A. Nat Genet 1995;10:119-121

8. Bi L, Sarkar R, Naas T, et al. Further characterization of factor VIII-deficient mice created by gene targeting: RNA and protein studies. Blood 1996;88:3446-3450

9. Wang L, Zoppe M, Hackeng TM, et al. A factor IX-deficient mouse model for hemophilia B gene therapy. Proc Natl Acad Sci USA 1997;94:11563-11566

10. Kundu RK, Sangiorgi F, Wu LY, et al. Targeted inactivation of the coagulation factor IX gene causes hemophilia B in mice. Blood 1998;92:168-174

11. Giles AR, Tinlin S, Hoogendoorn H, Greenwood P, Greenwood R. Development of factor VIII:C antibodies in dogs with hemophilia A (factor VIII:C deficiency). Blood 1984;63:451-456

12. Evans JP, Brinkhous KM, Brayer GD, Reisner HM, High KA. Canine hemophilia B resulting from a point mutation with unusual consequences. Proc Natl Acad Sci USA 1989;86: 10095-10099 
13. Bergelson JM, Cunningham JA, Droguett G, et al. Isolation of a common receptor for Coxsackie $B$ viruses and adenoviruses 2 and 5. Science 1997;275:1320-1323

14. Kozarsky KF, Wilson JM. Gene therapy: adenovirus vectors. Curr Opin Genet Dev 1993;3:499-503

15. Krougliak V, Graham FL. Development of cell lines capable of complementing $\mathrm{E} 1, \mathrm{E} 4$, and protein IX defective adenovirus type 5 mutants. Hum Gene Ther 1995;6:1575-1586

16. Berkner KL. Development of adenovirus vectors for the expression of heterologous genes. Biotechniques 1988;6:616629

17. Connelly S, Mount J, Mauser A, et al. Complete short-term correction of canine hemophilia A by in vivo gene therapy. Blood 1996;88:3846-3853

18. Lozier JN, Metzger ME, Donahue RE, Morgan RA. Adenovirus-mediated expression of human coagulation factor IX in the rhesus macaque is associated with dose-limiting toxicity. Blood 1999;94:3968-3975

19. National Institutes of Health Recombinant DNA Advisory Committee Assessment of adenoviral vector safety and toxicity. Hum Gene Ther 2002;13:3-13

20. Armentano D, Sookdeo CC, Hehir KM, et al. Characterization of an adenovirus gene transfer vector containing an E4 deletion. Hum Gene Ther 1995;6:1343-1353

21. Wang Q, Jia XC, Finer MH. A packaging cell line for propagation of recombinant adenovirus vectors containing two lethal gene-region deletions. Gene Ther 1995;2:775-783

22. Gao GP, Yang Y, Wilson JM. Biology of adenovirus vectors with E1 and E4 deletions for liver-directed gene therapy. J Virol 1996;70:8934-8943

23. Yeh P, Dedieu JF, Orsini C, et al. Efficient dual transcomplementation of adenovirus E1 and E4 regions from a 293derived cell line expressing a minimal E4 functional unit. J Virol 1996;70:559-565

24. Morral N, O'Neal W, Zhou H, Langston C, Beaudet A. Immune responses to reporter proteins and high viral dose limit duration of expression with adenoviral vectors: comparison of E2a wild type and E2a deleted vectors. Hum Gene Ther 1997;8:1275-1286

25. Fang B, Wang H, Gordon G, et al. Lack of persistence of E1recombinant adenoviral vectors containing a temperaturesensitive E2A mutation in immunocompetent mice and hemophilia B dogs. Gene Ther 1996;3:217-222

26. Gorziglia MI, Kadan MJ, Yei S, et al. Elimination of both E1 and $\mathrm{E} 2$ from adenovirus vectors further improves prospects for in vivo human gene therapy. J Virol 1996;70:4173-4178

27. Ye X, Gao GP, Pabin C, Raper SE, Wilson JM. Evaluating the potential of germ line transmission after intravenous administration of recombinant adenovirus in the $\mathrm{C} 3 \mathrm{H}$ mouse. Hum Gene Ther 1998;9:2135-2142

28. Lusky $\mathrm{M}$, Christ $\mathrm{M}$, Rittner $\mathrm{K}$, et al. In vitro and in vivo biology of recombinant adenovirus vectors with $\mathrm{E} 1, \mathrm{E} 1 / \mathrm{E} 2 \mathrm{~A}$, or E1/E4 deleted. J Virol 1998;72:2022-2032

29. Andrews JL, Kadan MJ, Gorziglia MI, Kaleko M, Connelly $\mathrm{S}$. Generation and characterization of $\mathrm{E} 1 / \mathrm{E} 2 \mathrm{a} / \mathrm{E} 3 / \mathrm{E} 4-$ deficient adenoviral vectors encoding human factor VIII. Mol Ther 2001;3:329-336

30. Lynch CM, Israel DI, Kaufman RJ, Miller AD. Sequences in the coding region of clotting factor VIII act as dominant inhibitors of RNA accumulation and protein production. Hum Gene Ther 1993;4:259-272

31. Hoeben RC, Fallaux FJ, Cramer SJ, et al. Expression of the blood-clotting factor-VIII cDNA is repressed by a transcrip- tional silencer located in its coding region. Blood 1995;85: 2447-2454

32. Kaufman RJ, Wasley LC, Dorner AJ. Synthesis, processing, and secretion of recombinant human factor VIII expressed in mammalian cells. J Biol Chem 1988;263:6352-6362

33. Connelly S, Smith TA, Dhir G, et al. In vivo gene delivery and expression of physiological levels of functional human factor VIII in mice. Hum Gene Ther 1995;6:185-193

34. Connelly S, Gardner JM, McClelland A, Kaleko M. Highlevel tissue-specific expression of functional human factor VIII in mice. Hum Gene Ther 1996;7:183-195

35. Connelly S, Gardner JM, Lyons RM, McClelland A, Kaleko M. Sustained expression of therapeutic levels of human factor VIII in mice. Blood 1996;87:4671-4677

36. Connelly S, Andrews JL, Gallo AM, et al. Sustained phenotypic correction of murine hemophilia A by in vivo gene therapy. Blood 1998;91:3273-3281

37. Connelly S, Andrews JL, Gallo-Penn AM, et al. Evaluation of an adenoviral vector encoding full-length human factor VIII in hemophiliac mice. Thromb Haemost 1999;81:234239

38. Gallo-Penn AM, Shirley PS, Andrews JL, et al. In vivo evaluation of an adenoviral vector encoding canine factor VIII: high-level, sustained expression in hemophiliac mice. Hum Gene Ther 1999;10:1791-1802

39. Gallo-Penn AM, Shirley PS, Andrews JL, et al. Systemic delivery of an adenoviral vector encoding canine factor VIII results in short-term phenotypic correction, inhibitor development, and biphasic liver toxicity in hemophilia A dogs. Blood 2001;97:107-113

40. Sarkar R, Gao GP, Chirmule N, Tazelaar J, Kazazian HH, Jr Partial correction of murine hemophilia A with neo-antigenic murine factor VIII. Hum Gene Ther 2000;11:881-894

41. Lipshutz GS, Sarkar R, Flebbe-Rehwaldt L, Kazazian H, Gaensler KM. Short-term correction of factor VIII deficiency in a murine model of hemophilia A after delivery of adenovirus murine factor VIII in utero. Proc Natl Acad Sci USA 1999;96:13324-13329

42. Brann T, Kayda D, Lyons RM, et al. Adenoviral vectormediated expression of physiologic levels of human factor VIII in nonhuman primates. Hum Gene Ther 1999;10:2999_ 3011

43. Andrews JL, Shirley PS, Iverson WO, et al. Evaluation of the duration of human factor VIII expression in nonhuman primates after systemic delivery of an adenoviral vector. Hum Gene Ther 2002;13:1331-1336

44. Kay MA, Landen CN, Rothenberg SR, et al. In vivo hepatic gene therapy: complete albeit transient correction of factor IX deficiency in hemophilia B dogs. Proc Natl Acad Sci USA 1994;91:2353-2357

45. Walter J, You Q, Hagstrom JN, Sands M, High KA. Successful expression of human factor IX following repeat administration of adenoviral vector in mice. Proc Natl Acad Sci USA 1996;93:3056-3061

46. Schneider H, Adebakin S, Themis M, et al. Therapeutic plasma concentrations of human factor IX in mice after gene delivery into the amniotic cavity: a model for the prenatal treatment of haemophilia B. J Gene Med 1999;1:424-432

47. Kung SH, Hagstrom JN, Cass D, et al. Human factor IX corrects the bleeding diathesis of mice with hemophilia B. Blood 1998;91:784-790

48. Dai Y, Schwarz EM, Gu D, et al. Cellular and humoral immune responses to adenoviral vectors containing factor IX 
gene: tolerization of factor IX and vector antigens allows for long-term expression. Proc Natl Acad Sci USA 1995;92: 1401-1405

49. Fields PA, Kowalczyk DW, Arruda VR, et al. Role of vector in activation of $\mathrm{T}$ cell subsets in immune responses against the secreted transgene product factor IX. Mol Ther 2000;1:225235

50. Lozier JN, Metzger ME, Donahue RE, Morgan RA. The rhesus macaque as an animal model for hemophilia B gene therapy. Blood 1999;93:1875-1881

51. Morral N, O’Neal WK, Rice K, et al. Lethal toxicity, severe endothelial injury, and a threshold effect with high doses of an adenoviral vector in baboons. Hum Gene Ther 2002;13:143154

52. Fang B, Eisensmith RC, Wang H, et al. Gene therapy for hemophilia B: host immunosuppression prolongs the therapeutic effect of adenovirus-mediated factor IX expression. Hum Gene Ther 1995;6:1039-1044

53. Smith TA, White BD, Gardner JM, Kaleko M, McClelland A. Transient immunosuppression permits successful repetitive intravenous administration of an adenovirus vector. Gene Ther 1996;3:496-502

54. Yang Y, Greenough K, Wilson JM. Transient immune blockade prevents formation of neutralizing antibody to recombinant adenovirus and allows repeated gene transfer to mouse liver. Gene Ther 1996;3:412-420

55. Morral N, O’Neal W, Rice K, et al. Administration of helperdependent adenoviral vectors and sequential delivery of different vector serotype for long-term liver-directed gene transfer in baboons. Proc Natl Acad Sci USA 1999;96: 12816-12821

56. Kochanek S, Clemens PR, Mitani K, et al. A new adenoviral vector: Replacement of all viral coding sequences with $28 \mathrm{~kb}$ of DNA independently expressing both full-length dystrophin and beta-galactosidase. Proc Natl Acad Sci USA 1996;93:5731-5736

57. Kochanek S. Development of high-capacity adenoviral vectors for gene therapy. Thromb Haemost 1999;82:547-551

58. Morsy MA, Gu M, Motzel S, et al. An adenoviral vector deleted for all viral coding sequences results in enhanced safety and extended expression of a leptin transgene. Proc Natl Acad Sci USA 1998;95:7866-7871

59. Schiedner G, Morral N, Parks RJ, et al. Genomic DNA transfer with a high-capacity adenovirus vector results in improved in vivo gene expression and decreased toxicity. Nat Genet 1998;18:180-183

60. Parks RJ, Chen L, Anton M, et al. A helper-dependent adenovirus vector system: removal of helper virus by Cremediated excision of the viral packaging signal. Proc Natl Acad Sci USA 1996;93:13565-13570

61. Parks RJ, Graham FL. A helper-dependent system for adenovirus vector production helps define a lower limit for efficient DNA packaging. J Virol 1997;71:3293-3298

62. Mitani K, Graham FL, Caskey CT, Kochanek S. Rescue, propagation, and partial purification of a helper virusdependent adenovirus vector. Proc Natl Acad Sci USA 1995;92:3854-3858

63. Clemens PR, Kochanek S, Sunada Y, et al. In vivo muscle gene transfer of full-length dystrophin with an adenoviral vector that lacks all viral genes. Gene Ther 1996;3:965-972

64. Chen HH, Mack LM, Kelly R, et al. Persistence in muscle of an adenoviral vector that lacks all viral genes. Proc Natl Acad Sci USA 1997;94:1645-1650
65. Lieber A, He CY, Kirillova I, Kay MA. Recombinant adenoviruses with large deletions generated by Cre-mediated excision exhibit different biological properties compared with first-generation vectors in vitro and in vivo. J Virol 1996;70:8944-8960

66. Zhang WW, Josephs SF, Zhou J, et al. Development and application of a minimal-adenoviral vector system for gene therapy of hemophilia A. Thromb Haemost 1999;82:562-571

67. Thomas CE, Schiedner G, Kochanek S, Castro MG, Lowenstein PR. Peripheral infection with adenovirus causes unexpected long-term brain inflammation in animals injected intracranially with first-generation, but not with highcapacity, adenovirus vectors: toward realistic long- term neurological gene therapy for chronic diseases. Proc Natl Acad Sci USA 2000;97:7482-7487

68. Balague C, Zhou J, Dai Y, et al. Sustained high-level expression of full-length human factor VIII and restoration of clotting activity in hemophilic mice using a minimal adenovirus vector. Blood 2000;95:820-828

69. Zou L, Zhou H, Pastore L, Yang K. Prolonged transgene expression mediated by a helper-dependent adenoviral vector (hdAd) in the central nervous system. Mol Ther 2000;2:105113

70. Reddy PS, Sakhuja K, Ganesh S, et al. Sustained human factor VIII expression in hemophilia A mice following systemic delivery of a gutless adenoviral vector. Mol Ther 2002;5:63-73

71. Chuah MK, Schiedner G, Thorrez L, et al. Therapeutic factor VIII levels and negligible toxicity in mouse and dog models of hemophilia A following gene therapy with high-capacity adenoviral vectors. Blood 2003;101:1734-1743

72. Ehrhardt A, Kay MA. A new adenoviral helper-dependent vector results in long-term therapeutic levels of human coagulation factor IX at low doses in vivo. Blood 2002;99: 3923-3930

73. Schnell MA, Zhang Y, Tazelaar J, et al. Activation of innate immunity in nonhuman primates following intraportal administration of adenoviral vectors. Mol Ther 2001;3:708722

74. Kafri T, Morgan D, Krahl T, et al. Cellular immune response to adenoviral vector infected cells does not require de novo viral gene expression: implications for gene therapy. Proc Natl Acad Sci USA 1998;95:11377-11382

75. Fang B, Andreason G, Hariharan M, et al. Pre-clinical efficacy and safety studies of a gutless adenovirus vector (MAXADFVIII) for treatment of haemophilia A. Thromb Haemost 2001;86:OC2490

76. VandenDriessche T, Collen D, Chuah MK. Viral vectormediated gene therapy for hemophilia. Curr Gene Ther 2001;1:301-315

77. Brown BD, Shi CX, Powell S, et al. Helper-dependent adenoviral vectors mediate therapeutic factor VIII expression for several months with minimal accompanying toxicity in a canine model of severe hemophilia A. Blood 2004;103:804810

78. Brown BD, Lillicrap D. Dangerous liaisons: the role of "danger" signals in the immune response to gene therapy. Blood 2002;100:1133-1140

79. Ehrhardt A, Xu H, Kay MA. Episomal persistence of recombinant adenoviral vector genomes during the cell cycle in vivo. J Virol 2003;77:7689-7695

80. Ehrhardt A, Xu H, Dillow AM, et al. A gene-deleted adenoviral vector results in phenotypic correction of canine 
hemophilia B without liver toxicity or thrombocytopenia. Blood 2003;102:2403-2411

81. Fechner H, Haack A, Wang H, et al. Expression of coxsackie adenovirus receptor and alpha $\mathrm{v}$-integrin does not correlate with adenovector targeting in vivo indicating anatomical vector barriers. Gene Ther 1999;6:1520-1535

82. Yant SR, Meuse L, Chiu W, et al. Somatic integration and long-term transgene expression in normal and haemophilic mice using a DNA transposon system. Nat Genet 2000;25: 35-41

83. Yant SR, Ehrhardt A, Mikkelsen JG, et al. Transposition from a gutless adeno-transposon vector stabilizes transgene expression in vivo. Nat Biotechnol 2002;20:999-1005

84. Shayakhmetov DM, Carlson CA, Stecher H, et al. A highcapacity, capsid-modified hybrid adenovirus/adeno-associated virus vector for stable transduction of human hematopoietic cells. J Virol 2002;76:1135-1143

85. Van Damme A, Chuah MKL, Collen D, VandenDriessche T. Onco-retroviral and lentiviral vector-based gene therapy for hemophilia: preclinical studies. Semin Thromb Hemost 2004;30:185-196

86. Krougliak VA, Krougliak N, Eisensmith RC. Stabilization of transgenes delivered by recombinant adenovirus vectors through extrachromosomal replication. J Gene Med 2001; 3:51-58

87. Kreppel F, Kochanek S. Episomally persisting high-capacity adenoviral vectors for prolonged transgene expression in proliferating cells. Mol Ther 2003;7:S192-S193

88. Bristol JA, Shirley P, Idamakanti N, Kaleko M, Connelly S. In vivo dose threshold effect of adenovirus-mediated factor VIII gene therapy in hemophiliac mice. Mol Ther 2000; 2:223-232

89. Tao N, Gao GP, Parr M, et al. Sequestration of adenoviral vector by Kupffer cells leads to a nonlinear dose response of transduction in liver. Mol Ther 2001;3:28-35
90. Kurt-Jones EA, Popova L, Kwinn L, et al. Pattern recognition receptors TLR4 and CD14 mediate response to respiratory syncytial virus. Nat Immunol 2000;1:398-401

91. Molinier-Frenkel V, Lengagne R, Gaden F, et al. Adenovirus hexon protein is a potent adjuvant for activation of a cellular immune response. J Virol 2002;76:127-135

92. Pastore L, Morral N, Zhou H, et al. Use of a liver-specific promoter reduces immune response to the transgene in adenoviral vectors. Hum Gene Ther 1999;10:17731781

93. De Geest BR, Van Linthout SA, Collen D. Humoral immune response in mice against a circulating antigen induced by adenoviral transfer is strictly dependent on expression in antigen- presenting cells. Blood 2003;101:2551-2556

94. Schiedner G, Bloch W, Hertel S, et al. Hemodynamic response to intravenous adenovirus vector particles caused by systemic Kupffer cell mediated activation of endothelial cells. Mol Ther 2003;7:S7

95. Fisher KD, Stallwood Y, Green NK, et al. Polymer-coated adenovirus permits efficient retargeting and evades neutralising antibodies. Gene Ther 2001;8:341-348

96. Croyle MA, Chirmule N, Zhang Y, Wilson JM. PEGylation of E1-deleted adenovirus vectors allows significant gene expression on readministration to liver. Hum Gene Ther 2002;13:1887-1900

97. Smith $\mathrm{T}$, Idamakanti $\mathrm{N}$, Kylefjord $\mathrm{H}$, et al. In vivo hepatic adenoviral gene delivery occurs independently of the coxsackievirus-adenovirus receptor. Mol Ther 2002;5:770779

98. Volpers C, Thirion C, Biermann V, et al. Antibody-mediated targeting of an adenovirus vector modified to contain a synthetic immunoglobulin g-binding domain in the capsid. J Virol 2003;77:2093-2104 